\title{
Rising Rate of Ceserean Section in Nepal
}

\author{
Article by Arju Chand Singh \\ Public Health, Texila American University \\ E-mail:arju.ravi@gmail.com
}

\begin{abstract}
Caesarean section is one of the most common and lifesaving surgeries performed in modern obstetrics. In a developing country like Nepal where health care resources are limited, this rising trend definitely has major implication but it is essential to perform when complications arise during pregnancy and labour without this large number of women and their unborn babies die every year, especially in low-income countries. The World Health Organization suggests 10-15\% cesarean section rate and has suggested to be done only when justified by a medical condition ${ }^{2}$. It states that, at a population level, if cesarean section rates higher than $10 \%$ does not reduce the maternal and neonatal mortality rates, and it should be performed only when medically justified. Otherwise unnecessary health of mother and babies including social and economic implications would challenge childbearing women, babies, their families and the state. Recently in Nepal there is a sharp rising trend of cesarean section rates from 20 to $81 \%$ in different hospitals especially in the private setting indicating over-medicalization of childbirth unnecessarily performing without medically justified. This arise the issue of human rights violence of childbearing women and professional integrity of a practitioner and safety of the clients. The World Health Organization recommended use of the Robson criteria which would be one of the best strategies in reducing the frequency of the procedure that should include avoidance of medically unnecessary primary cesarean section and improving case selection for induction and prelabour cesarean section besides educating childbearing women and their families about the consequences of unnecessary request of the procedure.
\end{abstract}

Keywords: Cesarean section; Rate; World health organization, Violence.

\section{Introduction}

A cesarean section is a life-saving obstetric emergency which is essential when certain complications arises during pregnancy and labour and without this, a large number of women and their unborn babies die every year, especially in low-income countries. Though, it is a major surgery and is associated with immediate maternal and perinatal risks and may have implications for future pregnancies as well as longterm effects that are still being investigated. The use of CS has increased dramatically worldwide in the last decades particularly in middle- and high-income countries, despite the lack of evidence supporting substantial maternal and perinatal benefits with CS rates higher than a certain threshold, and some studies showing a link between increasing CS rates and poorer outcomes. This marked increase in ceserean section rate may be due to excessive use of electronic fetal monitoring for early detection of fetal distress, practice for repeat ceserean section, doing ceserean section for most of the Breeches. Nevertheless, the World Health Organization (WHO) suggests that no region in the world is justified in having a cesarean section rate greater than $10-15 \%$. WHO statement concludes that cesarean sections are effective in saving maternal and infants lives, but only when they are required for medically indicated reasons. It states that, at a population level, cesarean section rates higher than $10 \%$ are not associated with reductions in maternal and newborn mortality rates, and it should be performed only when medically justified ${ }^{4}$. The reasons for this increase are multifactorial and not well-understood. Many studies have shown that women who underwent cesarean section without medical necessities are at increased risk of having infection, pain, pre-hospitalization, breastfeeding challenges, and complications in future pregnancies and even death. Additionally, babies delivered by cesarean sections have higher rates of hospital admission, need for ventilation, respiratory 
morbidity and mortality. Cesarean section born babies are more likely to have long-term negative health effects, such as asthma, type-1 diabetes, obesity, metabolic diseases and lead to unexplained stillbirths in the second pregnancy. These risks explain why cesarean on demand or without any maternal or fetal conditions is considered as an expensive and dangerous luxury, suggesting an urgency of controlling the rate of cesarean sections. Changes in maternal characteristics and professional practice styles, increasing malpractice pressure, as well as economic, organizational, social and cultural factors have all been implicated in this trend. Additional concerns and controversies surrounding CS include inequities in the use of the procedure, not only between countries but also within countries and the costs that unnecessary caesarean sections impose on financially stretched health systems.

The rate of cesarean sections around the world is increasing at an "alarming" rate. Since 1990, C-sections have more than tripled from about 6 percent of all births to 21 percent(three studies report in The Lancet). Now C-sections are more than vaginal deliveries in parts of southeast Europe, Latin America and China. Even in developing countries, the rates are extremely high at clinics. CS rates decreased only in two countries: Guinea, from 3.3\% to 2.4\%; and Nigeria, from $2.9 \%$ to $2 \%$. Zimbabwe maintained the rate at $6 \%$ and all other countries increased their use of $\mathrm{CS}^{5}$. Especially in Urban area, ceserean birth is in rising trend in Nepal. Studies have shown that women living in urban with higher levels of education, on highest wealth quantile and nulliparous are the one who are going through unnecessary cesarean delivery ${ }^{6,7}$.

In some hospitals like Patan Hospital and Tribhuvan University Teaching Hospital in Nepal there is increase in cesarean section rate from $23 \%$ in 2005 to $44 \%$ in 2014 and $17 \%$ in 2005 to $25 \%$ in 2010 respectively which indicate that there is declining in normal spontaneous and instrumental vaginal deliveries $^{8,9}$.This indicates that these women are becoming the victim of obstetric violence which is common in Nepal for which they are unaware because of their own ignorance and the medical professionals are becoming perpetrators ${ }^{10,11}$. Paradoxically, in rural Nepal women are facing life threating challenge to give complicated birth because of lack of access of obstetric emergency service where as in urban areas there is a medicalization of childbirth with unnecessary biomedical intervention treating physiological reproductive processes as biomedical problems that can be treated by the medical profession ${ }^{4}$. On enquiring about alarmingly increase in cesarean rates in Nepal some professionals, especially obstetricians assert mention that women prefer and request for cesarean delivery. However, studies in different settings including Nepal revealed that there was no valid evidence to prove that actually it is because of maternal request unnecessarily cesarean sections have been performed ${ }^{12}$. The American College of Obstetricians and Gynecologists ${ }^{13}$ clearly states that cesarean delivery on maternal request should not be recommended after knowing the potential risks of the procedure in the absence of maternal or fetal indications for cesarean delivery, a plan for vaginal delivery is safe and appropriate and should be recommended for clients.

Everyone working to improve maternal health care should have common goal that is healthy mothers and healthy babies; however, medical model of care can either protect or violate the fundamental human rights of childbearing women. There is a growing concern among women's rights and human rights advocates, and health research professionals regarding overmedicalization and commercialization of childbirth, particularly in the case of low risk pregnancy and that the cesarean section rate which has been recognized as a violation of human rights in childbirth and suggesting for social model of care to empower childbearing women ${ }^{14}$.In Bangladesh, India, Nepal and Pakistan only 15\%, 39\%, 37\% and 35\% of the recorded deliveries occurred in a health facility, respectively. However, many of these deliveries probably took place in private hospitals, where obstetricians and general practitioners are available to lead delivery care and the incentives to perform caesarean sections may be relatively greater. This may explain why such large proportions of the women who delivered in health facilities in Bangladesh, India, Nepal and Pakistan $-51 \%, 22 \%, 12 \%$ and $20 \%$, respectively - had caesarean sections ${ }^{15,16}$

Fear of litigation and professional agreements and disagreements were one of the key factors in the decision-making process. Insufficient human and physical resources, lack of unified guidelines, financial benefits to the hospital, and private versus public health care facilities were the contributing factors to the rise in rate of $\mathrm{CS}$. 
Nepal Context

Table 1. Percentage of cesarean section in different hospitals of Nepal

\begin{tabular}{|l|l|}
\hline Location and Hospitals & Rate in Percentage \\
\hline Om Hospital, Chabahil, Kathmandu & $81 \%$ \\
\hline Medicare Hospital, Chabahil, Kathmandu & $79 \%$ \\
\hline Valley Maternity Nursing Home & $77 \%$ \\
\hline B \& B Hospital & $67 \%$ \\
\hline Nepal Police Hospital, Kathmandu & $64 \%$ \\
\hline Kathmandu Model Hospital & $60 \%$ \\
\hline Kritipur Hospital (managed by Phect Nepal), Kathmandu & $51 \%$ \\
\hline Patan Hospital, Lagankel, Lalitpur & $47 \%$ \\
\hline Kathmandu Medical College, Sinamangal, Kathmandu & $46 \%$ \\
\hline Civil Service Hospital, New Baneshwor, Kathmandu & $45 \%$ \\
\hline TU Teaching Hospital, Maharajgunj, Kathmandu & $39 \%$ \\
\hline Shree BirendraSainik Hospital (Army Hospital), Kathmandu & $33 \%$ \\
\hline BP Koirala Institute of Health Science, Dharan & $30 \%$ \\
\hline Nobel Medical College Hospital, Biratangar, Morang & $20 \%$ \\
\hline $\begin{array}{l}\text { Paropakar Maternity and Women's Hospital (PMWH), } \\
\text { Thapathali }\end{array}$ & $17 \%$ \\
\hline $\begin{array}{l}\text { Karnali Academy of Health Sciences (KAHS) Teaching } \\
\text { Hospital, Jumla }\end{array}$ & $15 \%$ \\
\hline World Health Organization & $10-15 \%$ \\
\hline
\end{tabular}

The rise in the cesarean rate is commonly attributed to several factors which includes multiple gestation, maternal obesity, preterm labor, gestational diabetes, or hypertension-as well as physicians' concerns about liability and malpractice. But evidence indicates that these factors do not fully account for the wide differences in cesarean rates observed across states and countries. In 2012, about 23 million C-sections were done globally. Few evidences suggest a higher rate of $19 \%$ which may result in better outcomes. More than 45 countries globally have $\mathrm{C}$-section rates less than $7.5 \%$, while more than 50 have rates greater than $27 \%$. Efforts have been made to improve access to and reduce the use of C-section.

The National Institutes of Health, policy leaders, and clinicians have expressed concern over increasing cesarean rates. Healthy People 2020 initiative, the Department of Health and Human Services put forth clear, authoritative public health goals recommending a 10 percent reduction in both primary and repeat cesarean rates, from 26.5 percent to 23.9 percent, and from 90.8 percent to 81.7 percent, respectively.

Health care providers, patients, and policy makers should recognize these variations which is an important indicator of health care quality. Such variation may provide potential underuse or overuse of a service, both of which may be clinically harmful and costly. Understanding the extent of variation and its causes may provide opportunities for identifying policy options to improve care.

The prevalence of caesarean section is generally agreed to be higher than needed in many countries, and physicians are encouraged to actively lower the rate, as a caesarean rate higher than $10-15 \%$ is not associated with reductions in maternal or infant mortality rates whereas some evidence supports a higher rate of $19 \%$ may result in better outcomes.

\section{Conclusion}

Caesarean sections should ideally only be undertaken when medically necessary and every effort should be made to provide caesarean sections to women in need, rather than striving to achieve a specific rate. To slow down the increasing rate of cesarean section in Nepal, the government of Nepal should develop specific policies and measures, need to educate people about its pro and con. Additionally, use of WHO 
DOI: 10.21522/TIJPH.2013.SE.19.01.Art007

ISSN: $2520-3134$

proposes the Robson criteria as a standard for assessing, monitoring and comparing cesarean section rates within healthcare facilities overtime, and between facilities would assist in managing cesarean section rates at both the individual facility and national level by identifying how use of this intervention in specific obstetric subpopulations affects overall cesarean section rates, and how obstetric populations and intervention rates change with time ${ }^{17,18}$.Healthcare policy makers and professionals need to be called urgently to investigate and monitor its economic, social and medical implications for the society and nation to find out the causes of increasing rate of cesarean delivery in Nepal.

According to the latest data from 150 countries, currently $18.6 \%$ of all births occur by CS, ranging from $6 \%$ to $27.2 \%$ in the least and most developed regions, respectively. Latin America and the Caribbean region have the highest CS rates (40.5\%), followed by Northern America (32.3\%), Oceania (31.1\%), Europe (25\%), Asia (19.2\%) and Africa (7.3\%). Based on the data from 121 countries, the trend analysis showed that between 1990 and 2014, the global average CS rate increased 12.4\% (from 6.7\% to 19.1\%) with an average annual rate of increase of $4.4 \%$. The largest absolute increases occurred in Latin America and the Caribbean (19.4\%, from $22.8 \%$ to $42.2 \%$ ), followed by Asia (15.1\%, from $4.4 \%$ to $19.5 \%$ ), Oceania (14.1\%, from $18.5 \%$ to $32.6 \%$ ), Europe (13.8\%, from $11.2 \%$ to $25 \%$ ), Northern America (10\%, from $22.3 \%$ to $32.3 \%$ ) and Africa (4.5\%, from 2.9\% to $7.4 \%$ ). Asia and Northern America were the regions with the highest and lowest average annual rate of increase (6.4\% and $1.6 \%$, respectively).

\section{Conclusion}

The use of CS worldwide has increased to unprecedented levels although the gap between higher- and lower-resource settings remains. The information presented is essential to inform policy and global and regional strategies aimed at optimizing the use of CS.

\section{References}

[1]. Amatya A, Paudel R, Poudyal A, Wagle RR, Singh M, et al. (2013) Examining stratified cesarean section rates using Robson classification system at Tribhuvan University Teaching Hospital. J Nepal Health Res Counc 11(25): 255-258.

[2]. Caesarean sections. Postnote No. 184. London: Parliamentary Office of Science and Technology; 2002. Available from: http://www.parliament.uk/post/pn184.pdf.

[3]. C Black, JA Kaye, H Jick. Betrán AP, Ye J, Moller AB, Zhang J, Gülmezoglu AM, et al. (2016) The increasing trend in cesarean Section Rates: Global, Regional and National Estimates: 1990-2014. PLoS ONE 11(2): e0148343.

[4]. Data and sourcesS1 File. First and latest available CS rate data points per country, the year, total number of data points used for this analysis and sources of the data.

[5]. Lamichhane B, Singh A (2014) Changing trend in instrumental vaginal deliveries at Patan Hospital. Nepal J Obstet Gynaecol 20(2): 22-35.

[6]. Lokugamage AU, Pathberiya SDC (2017) Human rights in childbirth, narratives and restorative justice: a review. Rep Health 14: 17.

[7]. Montagu D, Yamey G, Visconti A, Harding A, Yoong J. Where do poor women in developing countries give birth? A multi-country analysis of demographic and health survey data. PLoS One 2011; 6: e17155.

[8]. Ministry of Health (2017) Nepal demographic and health survey 2016. Ministry of Health, Nepal.

[9]. Ministry of Health (2012) Nepal demographic and health survey 2011. Ministry of Health, Nepal.

[10]. Perez DR (2010) Obstetric violence: a new legal term introduced in Venezuela. Int J Gynecol Obstet 111(3): 201-202.

[11]. Parkhurst JO, Rahman SA. Lifesaving or money wasting? Perceptions of caesarean sections among users of services in rural Bangladesh. Health Policy2007; 80: 392-401.

[12]. Pope TM (2017) Legal Briefing: unwanted cesareans and obstetric violence. J Clin Ethics 28(2): 163-173. 33.

[13]. Robson MS (2001) Can we reduce the cesarean section rate? Best Pract Res ClinObstet Gynecol 15(1): $179-194$. [14]. Schantz C, Sim KL, Petit V, Rany H, Goyet S (2016) Factors associated with cesarean sections in Phnom Penh, Cambodia. Rep Health Matters 24(48): 111-121-44. 
[15]. The American College of Obstetrics and Gynecology Committee on Obstetric Practice, The Society for Maternal-Fetal Medicine. (2013) Committee Opinion Number 561: Nonmedically Indicated Early-Term Deliveries. Obstet Gynecol 121: 911-915.

[16]. Vogel JP, Betran AP, Vindevoghel N, Souza JP, Torloni MR, et al. (2015) Use of the Robson classification to assess cesarean section trends in 21 countries: a secondary analysis of two WHO multicountry surveys. The Lancet Global Health 3(5): e260-e270.

[17]. World Health Organization. Appropriate technology for birth. Lancet 1985; 2(8452):436-7.

[18]. WHO World Health Organisation (2015) WHO Statement on cesarean section rates. 